\title{
Shrinkage in Ultra-High Performance Concrete Overlays on Concrete Bridge Decks
}

\author{
William Toledo, Leticia Davila, Ahmed Al-Basha, Craig Newtson*, and Brad Weldon \\ Department of Civil Engineering, New Mexico State University, Las Cruces, NM 88003
}

\begin{abstract}
This paper investigates the shrinkage and thermal effects of an ultra-high performance concrete (UHPC) mixture proposed for use as an overlay material for concrete bridge decks. In this study, early-age and longer-term shrinkage tests were performed on the locally produced UHPC. Thermal and shrinkage effects in normal strength concrete slabs overlaid with UHPC were also observed. Early-age shrinkage testing showed that approximately $55 \%$ of the strain occurred in the plastic state and may not contribute to bond stresses since the elastic modulus of the UHPC should be small at such early ages. Thickness of the substrate and amount of reinforcing steel were important factors for shrinkage in the slabs. The thickest slab experienced greater shrinkage than thinner slabs. Comparing this slab to a thinner slab with the same reinforcement indicated that reinforcement ratio is more important than the area of steel.
\end{abstract}

\section{Introduction}

A major issue facing the world's infrastructure is rapidly degrading concrete bridge decks. Concrete bridge decks can be exposed to a wide range of environmental and mechanical distress and are critical bridge elements since they not only provide a comfortable and safe riding surface but also protect structural elements beneath them. According to 2016 United States National Bridge Inventory data, $23.9 \%$ of US bridges have concrete bridge decks in "Satisfactory" condition and only 10 out of 43 transportation agencies anticipate that their bridge deck overlays have service lives greater than 25 years [1].

Ultra-high performance concrete (UHPC) has exceptional mechanical and durability properties [1-4] that provide the potential to greatly improve the service lives of existing bridge decks. The use of locally available materials can also make non-proprietary UHPC more economical and sustainable compared to proprietary UHPC products [5]. The work presented in this paper investigated the potential for using a locally produced UHPC as an overlay material to rehabilitate concrete bridge decks.

\section{Background}

UHPC is a modern concrete exhibiting exceptional mechanical and durability properties. These properties include compressive strength greater than $120 \mathrm{MPa}$ $(17,000 \mathrm{psi})$ [6], high ductility when fiber reinforced, and excellent resistance to frost damage, alkali-silicareaction, and abrasion $[2,7,8]$. UHPC's properties are achieved through careful selection of its constituent materials to ensure optimized gradation and maximized packing density as well as detailed preparation methods to properly mix and cure UHPC elements [9]. UHPC's unique properties provide the potential to significantly improve service lives and durability of existing concrete bridge decks.

UHPC is known to shrink substantially [10]. UHPC shrinkage can cause shear and tensile stresses at the bond interface that could, in turn, cause cracks and delamination at the bond. Since ACI 546 [11] recommends using an overlay material that can shrink without losing bond [11], it is important to quantify the shrinkage effects of UHPC on normal strength concrete (NSC) substrates.

\section{Methodology}

UHPC mixture proportions. The mixture that provided sufficient workability and strength was a mixture that used a w/cm ratio of 0.15 , with $20 \%$ supplementary cementitious materials that were composed of $50 \%$ silica fume and $50 \%$ fly ash, and a local sand. The mixture proportions for the UHPC mixture used in this study are presented in Table 1.

Early-age shrinkage. Shrinkage in the UHPC is important because it will cause shear stress on the bond between the overlay material and the mature substrate concrete. Shrinkage of the overlay material can also cause curling, which can produce direct tension on the bond between the overlay and the substrate.

No standard test specifications are available for early-age shrinkage testing, so a test method developed

\footnotetext{
* Corresponding author: newtson@,nmsu.edu
} 
by Holt [12] was adopted. The early-age shrinkage specimen was a $152 \times 152 \times 610 \mathrm{~mm}(6 \times 6 \times 24$ in. $)$ UHPC beam. The testing apparatus consisted of a steel frame that was placed over the mold for the UHPC shrinkage specimen so that it spanned the mold in the longitudinal direction. The beam mold was lined with plastic, talc powder, and another layer of plastic to minimize friction between the UHPC shrinkage specimen and the beam mold. As the UHPC shrinkage specimen was cast, steel hangers supported by the steel frame were embedded into the UHPC beam to a depth of $38 \mathrm{~mm}(1.5 \mathrm{in}$.) at a location that was $25 \mathrm{~mm}$ (1.0 in.) from the ends of the beam mold. Linearly variable displacement transducers (LVDTs) that were supported by the steel frame were used to monitor movement of the hangers caused by shrinkage. A photograph and illustration of the experimental setup for the early-age shrinkage test is shown in Figure 1.

Table 1. UHPC mixture proportions.

\begin{tabular}{|c|c|}
\hline Material & $\mathbf{k g} / \mathbf{m}^{\mathbf{3}}\left(\mathbf{l b} / \mathbf{y d} \mathbf{d}^{\mathbf{3}}\right)$ \\
\hline Cement & $817(1377)$ \\
\hline Silica Fume & $102(172)$ \\
\hline Fly Ash & $102(172)$ \\
\hline Sand & $1009(1702)$ \\
\hline $\begin{array}{c}\text { HRWRA } \\
\mathrm{L} / \mathrm{m}^{3}\left(\mathrm{gal}^{\mathrm{yd}} \mathrm{y}^{3}\right)\end{array}$ & $45(9.09)$ \\
\hline Water & $153(258)$ \\
\hline Steel Fibers & $119(201)$ \\
\hline
\end{tabular}
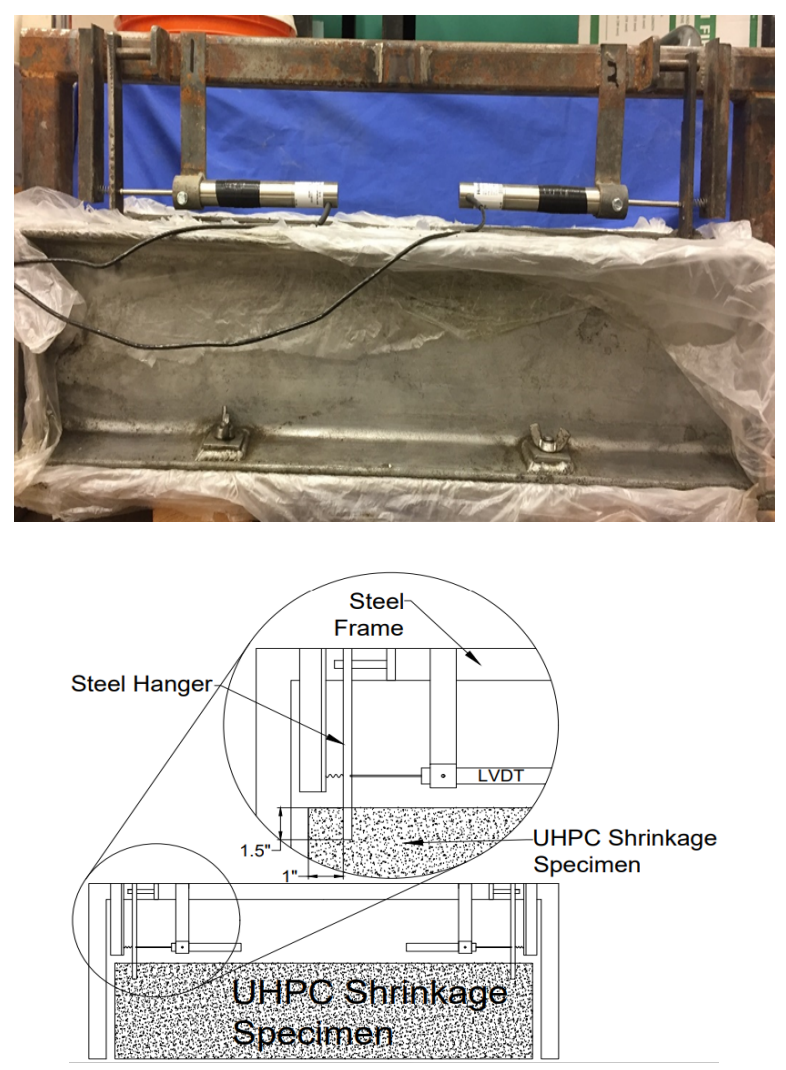

Fig. 1. Early-age shrinkage setup (top), illustration of setup (bottom).
The early-age shrinkage test ran for seven days with LVDT readings collected every 15 seconds. The gauge length of the specimen was $559 \mathrm{~mm}$ (22 in.), from hanger to hanger. The change in length of the specimen was computed using the measurements of the two LVDTs shown in Figure 1.

Longer-term shrinkage. Longer-term shrinkage in overlay concrete also contributes to shear stresses and direct tension on the bonded interface. Therefore, longer-term shrinkage of UHPC was also characterized. Longer-term shrinkage was measured according to ASTM C157 [13]. The longer-term shrinkage specimens were $76 \times 102 \times 406 \mathrm{~mm}(3 \times 4 \times 16$ in.) prisms with gauge studs (contact points) cast into the ends of the specimens. After curing in the mold for 24 hours, the longer-term UHPC shrinkage specimens were cured in a wet room for seven days. After the seven-day wet cure, the specimens were placed in ambient conditions $\left[20^{\circ} \mathrm{C}\right.$ $\left(68^{\circ} \mathrm{F}\right)$ and $30 \%$ relative humidity] for the remainder of the shrinkage monitoring.

Longer-term shrinkage test. Testing began immediately after the beams were removed from the molds. Deformation was monitored using a comparator as shown in Figure 2. Measurements were recorded every day for 28 days, which included the seven days curing in a wet room and the remaining days curing at ambient conditions.

Slab tests. To investigate the combined effects of temperature and shrinkage on slabs with UHPC overlays, the behaviors of five NSC reinforced slabs with dimensions of $0.9 \times 0.9 \mathrm{~m}(3 \times 3 \mathrm{ft}$.$) with varied$ thicknesses were monitored. Each slab had a reinforcement mesh consisting of six No. 10 (No. 3) bars, three in each direction (transverse and longitudinal). The slab design and instrumentation layout is illustrated in Figure 3. Specimen parameters that were varied included exposure condition, thickness of NSC slab, reinforcement bar size, and application of overlay. The specific characteristics for each slab are provided in Table 2, and were selected such that at least two slabs can be compared with just a single parameter variation per pair of slabs. All slabs used the same NSC mixture proportions, provided by a local ready-mix company presented in Table 3 and had a water-to-cement ratio of 0.39 .

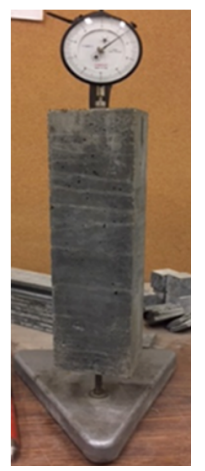

Fig. 2. Longer-term shrinkage test setup. 


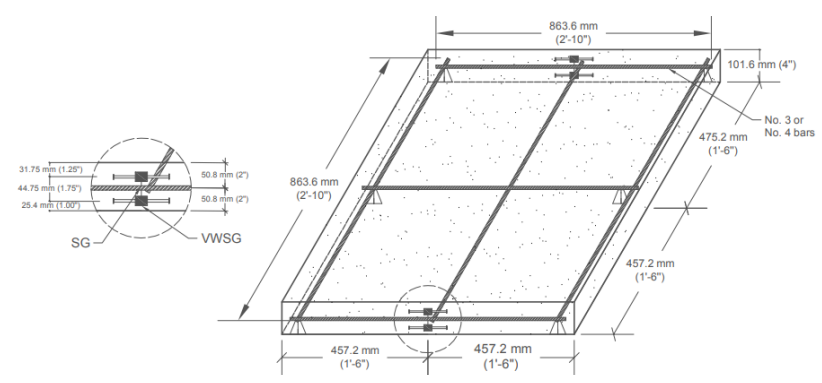

Fig. 3. Slab design and instrumentation layout.

Two types of sensors were used in this research, strain gauges with a length of $2 \mathrm{~mm}$ ( $0.08 \mathrm{in}$.) attached to the steel reinforcement, and vibrating wire strain gauges (VWSGs) with lengths of $171 \mathrm{~mm}$ (6.75 in.). VWSG frequency was measured by sensors connected to a datalogger. The change in frequency was recorded at 10minute intervals, which was the average of the change in frequency measured every two minutes within the 10minute period. The average change in frequency was used to determine the strain in the substrate.

Table 2. Characteristics for each slab.

\begin{tabular}{|c|c|c|c|c|c|c|c|}
\hline \multirow{2}{*}{ Specimen } & \multirow{2}{*}{$\begin{array}{l}\text { Exposure } \\
\text { Condition }\end{array}$} & \multicolumn{2}{|c|}{\begin{tabular}{|c|} 
Thickness \\
NSC \\
\end{tabular}} & \multirow{2}{*}{$\begin{array}{l}\text { Bar } \\
\text { size }\end{array}$} & \multirow{2}{*}{ Overlay } & \multicolumn{2}{|c|}{\begin{tabular}{|c|} 
Thickness \\
UHPC
\end{tabular}} \\
\hline & & (mm) & (in) & & & $(\mathbf{m m})$ & (in) \\
\hline Slab 1 & Controlled & 101.6 & 4 & No. 3 & Yes & 25.4 & 1 \\
\hline Slab 2 & Controlled & 101.6 & 4 & No. 3 & No & - & - \\
\hline Slab 3 & Environmental & 101.6 & 4 & No. 4 & Yes & 25.4 & 1 \\
\hline Slab 4 & Environmental & 152.4 & 6 & No. 4 & Yes & 25.4 & 1 \\
\hline Slab 5 & Environmental & 101.6 & 4 & No. 3 & Yes & 25.4 & 1 \\
\hline
\end{tabular}

Table 3. NSC mixture proportions.

\begin{tabular}{|c|c|c|c|c|c|}
\hline Material & Cement & Fly Ash & Sand & $\begin{array}{c}\text { Coarse } \\
\text { Aggregate }\end{array}$ & Water \\
\hline $\begin{array}{c}\mathbf{k g} / \mathbf{m}^{\mathbf{3}} \\
\left(\mathbf{l b} / \mathbf{f t}^{\mathbf{3}}\right)\end{array}$ & $\begin{array}{c}230 \\
(14.4)\end{array}$ & $\begin{array}{c}57.6 \\
(3.60)\end{array}$ & $\begin{array}{c}556 \\
(34.7)\end{array}$ & $\begin{array}{c}794 \\
(49.6)\end{array}$ & $\begin{array}{c}113 \\
(7.05)\end{array}$ \\
\hline
\end{tabular}

\section{Results and discussion}

Early-age shrinkage. Figure 4 presents the early-age shrinkage results collected for 24 hours. It is difficult to establish set times for UHPC mixtures because they can be extremely viscous in the fluid state. By stripping molds at early ages and watching for slumped specimens, the set time for the UHPC mixture is estimated to be 10 hours. During the first 10 hours, the UHPC is in a plastic state that may not transfer shear stress to the substrate concrete. Consequently, it appears that although the early-age shrinkage is substantial, approximately 55\% (roughly $1000 \mu$ strain) of it occurs in the plastic state and may not contribute to bond stresses since the elastic modulus of the UHPC should be small at such early ages. Similar early-age shrinkage tests conducted by Allena and Newtson [10] produced results in the first 24 hours comparable to those observed in this study.
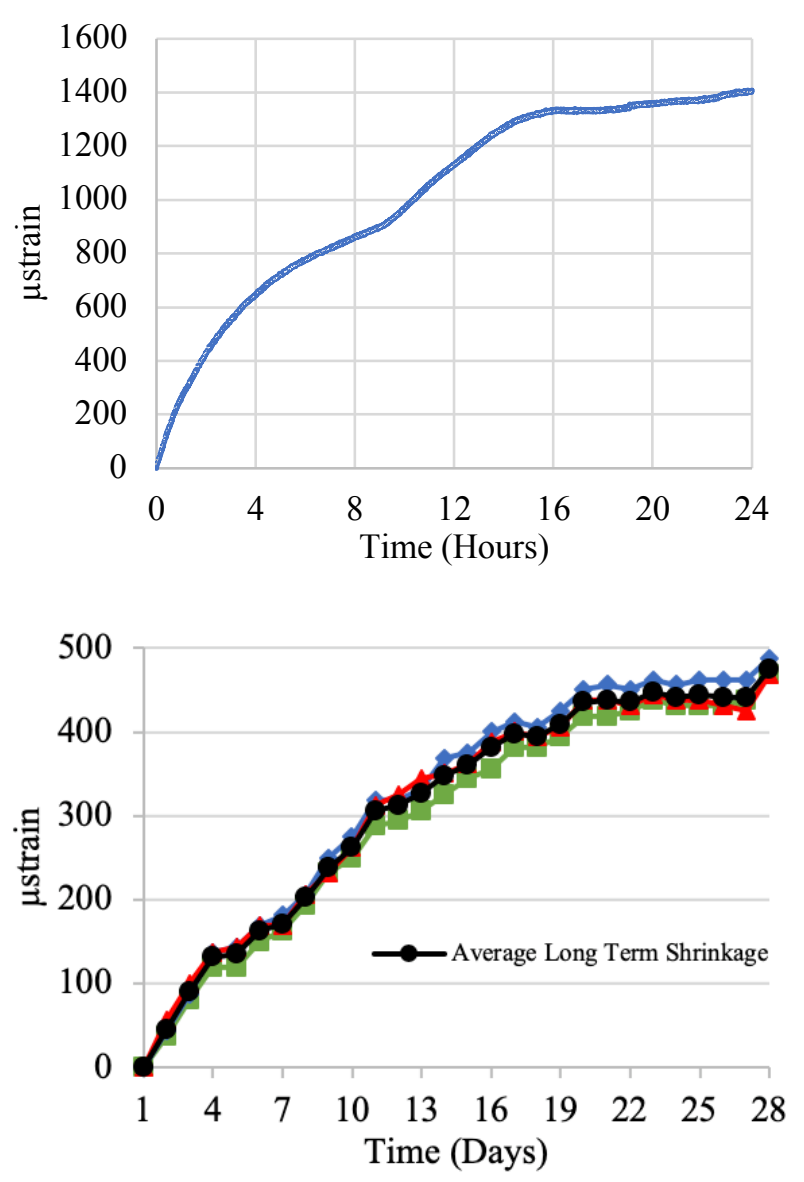

Fig. 3. Shrinkage results: early-age (top) and longer-term (bottom).

Longer-term shrinkage. The longer-term shrinkage test was conducted on $76 \times 102 \times 406 \mathrm{~mm}(3 \times 4 \times 16$ in.) UHPC prisms. The tests were conducted for 28 days, taking readings using a comparator once a day. Figure 4 presents the results of the longer-term shrinkage test. The specimens were cured for seven days in the wet room then taken out and cured in ambient conditions for the remainder of the test. As seen in the plot, the shrinkage plateaus around four days. However, shrinkage resumed once the specimens were exposed to drying. The shrinkage began to plateau again around 20 days at approximately 450 microstrain.

Slab tests. Figure 5a-5e show strain versus time plots for Slabs 1-5, respectively. The principal events that the slabs experienced from the casting day until the last recorded data day are noted on the Figures. The gap from day 54 to 76 in Figures $5 \mathrm{a}$ and $5 \mathrm{~b}$ for Slabs 1 and 2 is due to loss of power. A jump in strain occurred at day seven when the formwork was removed. At day 27, the slabs were exposed to environmental conditions (moved from inside the laboratory to outdoors) to prepare for the overlay placement. The environmental change at day 27 caused the specimens to experience more fluctuation in strain due to greater changes in temperature. At day 37 , when the overlay was placed, sensors near the tops of the slabs had smaller strains (around $-200 \mu \varepsilon$ ) than the sensors at the bottom (approximately $-350 \mu \varepsilon$ ). This behavior is attributed to wet curing that appears to have caused expansion at the top surface, and the bottom 
sensors were less sensitive to that moisture. The last event that Slabs 1 and 2 were subjected to was controlled exposure (these slabs were moved back into the laboratory). The controlled temperature in the laboratory reduced fluctuations in temperature and, subsequently, strain.

Slab 2 was not overlaid so that the effects of the overlays on the other slabs could be isolated. When Slab 1 was placed in a controlled environment, it experienced less strain and less fluctuation in strain than the other slabs. The strains in Slab 4 (Figure 5d) were approximately $22 \%$ greater than the measured strains in Slab 3 (Figure 5c) although the thicker substrate was expected to provide greater restraint. This observation is attributed to having a smaller reinforcement ratio in Slab 4 than in Slab 3. Comparing Slab 3 (Figure 5c) and Slab 5 (Figure 5e) showed that the measured strains were greater in the substrate that contained less steel (Slab 5).

\section{Conclusions}

The following conclusions were drawn from this work:

1. The early-age shrinkage test showed that approximately $55 \%$ of the strain occurred in the plastic state, so much of this early-age shrinkage may not contribute to bond stresses since the elastic modulus of the UHPC would be small at such early ages.

2. The reinforcement used in the slabs is relevant for shrinkage. As expected, slabs experienced less shrinkage when more steel was provided.

3. Thickness of the substrate was also an important factor for shrinkage. The thickest slab experienced greater shrinkage than thinner slabs. This indicated that reinforcement ratio is more important than reinforcement area since comparable slabs contained the same amount of steel.

4. The slab that was exposed only to laboratory conditions experienced shrinkage that was more uniform, as expected.

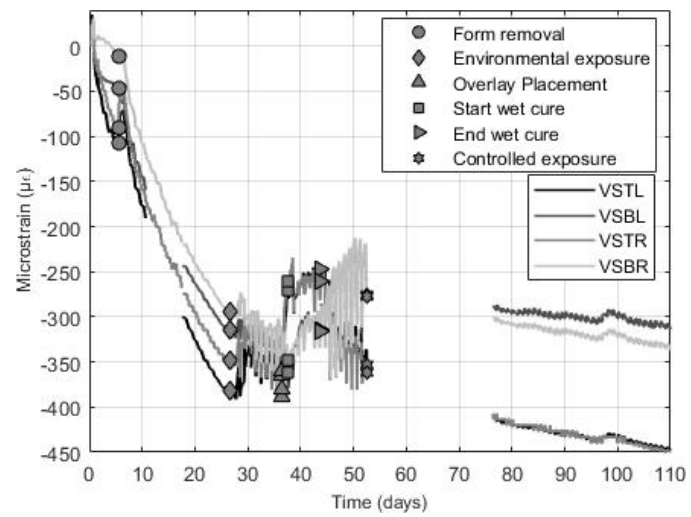

(a)

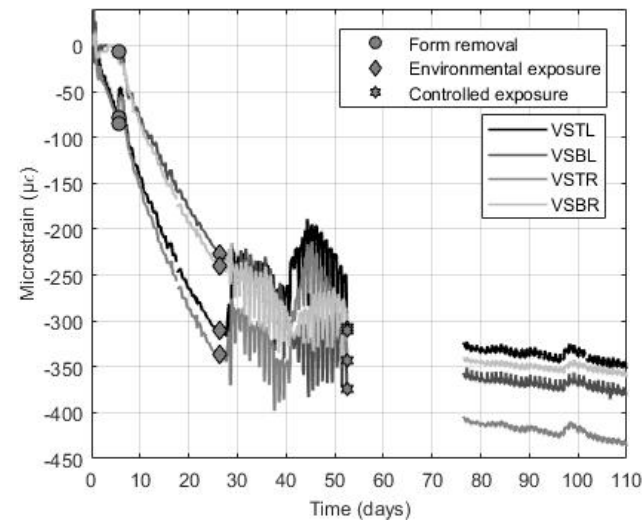

(b)

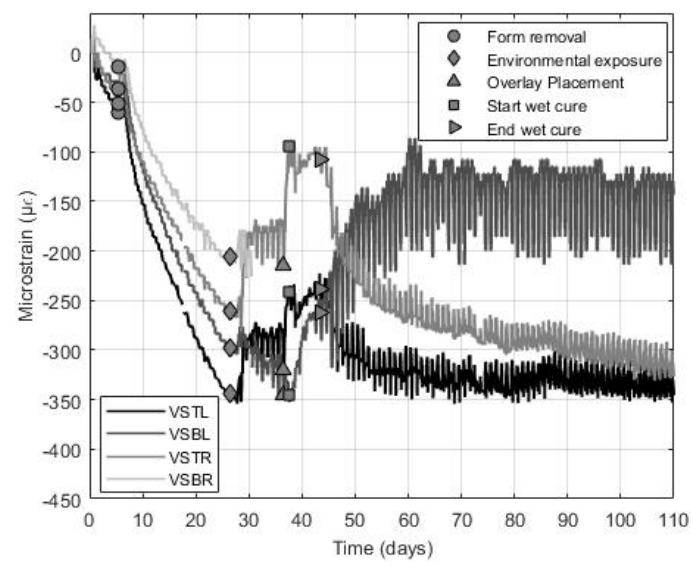

(c)

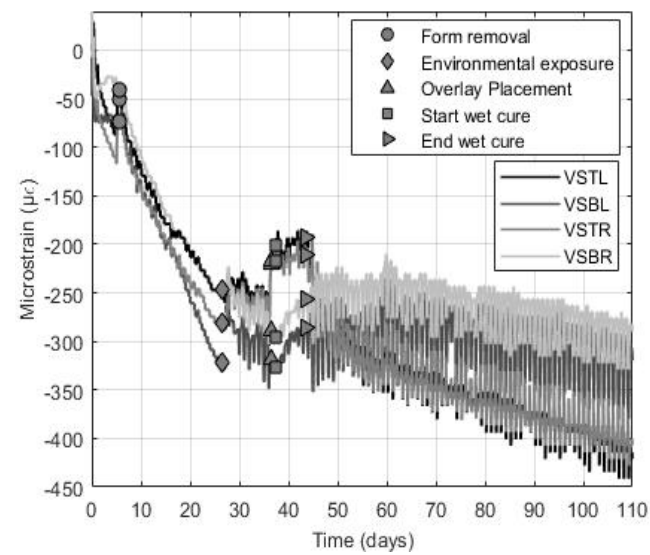

(d)

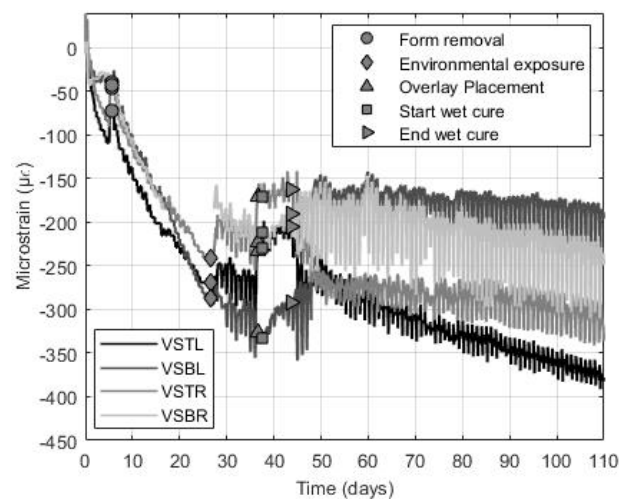

(e)

Fig. 5. Strain versus time in slab 1-5 (a-e). 
The authors would like to thank Tran-SET for funding this project, the New Mexico Department of Transportation for their continued support of UHPC research and collaboration, and BASF Chemical Company for their donations of silica fume and admixtures.

\section{References}

1. Haber, Z.B., Graybeal, B.A., and Munoz, J.F. (2017). Field Testing of an Ultra-High Performance Concrete Overlay. FHWA-HRT-17-096, Federal Highway Administration.

2. Magureanu, C., Sosa, I., Negrutiu, C., and Heghes, B. (2012). Mechanical Properties and Durability of Ultra-High-Performance Concrete. ACI Materials Journal, 109(2), 177-183.

3. Naaman, A.E., and Wille, K. (2012). The path to Ultra-High performance Fibre Reinforced Concrete (UHP-FRC): Five Decades of Progress. Third International Symposium on UHPC and Nanotechnology for High Performance Construction Materials, Kassel, 3-15.

4. Shann, S.V., Harris, D.K., Carbonell, M.C., and Ahlborn, T.M. (2012). Application of UHPC as a Thin Topped Overlay for Concrete Bridge Decks. Third International Symposium on UHPC and Nanotechnology for High Performance Construction Materials, 929-936.

5. Montoya, K.F. (2010). Feasibility of Using Ultra High Performance Concrete in New Mexico Bridge Girders. Master's thesis, New Mexico State University.

6. ASTM C1856, (2017). Fabricating and Testing of Ultra-High Performance Concrete. Annual Book of ASTM Standards, ASTM International, Conshohocken, PA.

7. Villanueva, J.M. (2015). Mixture Proportioning and Freezing and Thawing Durability of Ultra High Performance Concrete Using Local Materials. Ph.D. dissertation, New Mexico State University.

8. Way, R., and Wille, K. (2012). Material Characterization of an Ultra High-PerformanceFibre Reinforced Concrete under Elevated Temperatures. Third International Symposium on UHPC and Nanotechnology for High Performance Construction Materials, Kassel, 565-572.

9. Al-Basha, A.J. (2017). Frost Resistance of Concrete Cladded with Locally Produced Ultra-High Performance Concrete Cured at Elevated Temperatures. Master's thesis, New Mexico State University.

10. Allena, S., and Newtson, C.M. (2011). Shrinkage of Fiber-Reinforced Ultrahigh Strength Concrete. Journal of Materials in Civil Engineering, 24(5), 612-614.

11. ACI Committee 546R-04 (2004). Guide to Materials Selection for Concrete Repair, American Concrete Institute. ACI546R-04.

12. Holt, E.E., (2001). Early Age Autogenous Shrinkage of Concrete. VTT publication 446, Technical Research Centre of Finland.
13. ASTM C157, (2017). Length Change of Hardened Hydraulic-Cement Mortar and Concrete. Annual Book of ASTM Standards, ASTM International, Conshohocken, PA. 